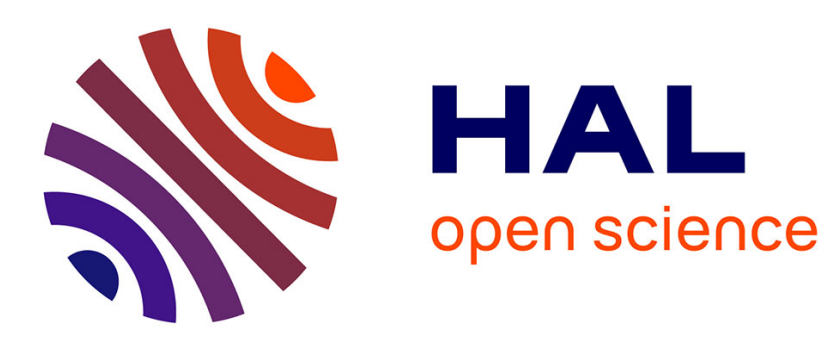

\title{
Demystifying the Atomistic Origin of the Electric Field Effect on Methane Oxidation
}

Christopher Panaritis, Yasmine M Hajar, Laureline Treps, Carine Michel, Elena A Baranova, Stephan N. Steinmann

\section{To cite this version:}

Christopher Panaritis, Yasmine M Hajar, Laureline Treps, Carine Michel, Elena A Baranova, et al. Demystifying the Atomistic Origin of the Electric Field Effect on Methane Oxidation. Journal of Physical Chemistry Letters, 2020, 11 (17), pp.6976-6981. 10.1021/acs.jpclett.0c01485 hal-02989601

\section{HAL Id: hal-02989601 \\ https://hal.science/hal-02989601}

Submitted on 5 Nov 2020

HAL is a multi-disciplinary open access archive for the deposit and dissemination of scientific research documents, whether they are published or not. The documents may come from teaching and research institutions in France or abroad, or from public or private research centers.
L'archive ouverte pluridisciplinaire HAL, est destinée au dépôt et à la diffusion de documents scientifiques de niveau recherche, publiés ou non, émanant des établissements d'enseignement et de recherche français ou étrangers, des laboratoires publics ou privés. 


\section{Demystifying the Atomistic Origin of the Electric Field Effect on Methane Oxidation}

Christopher Panaritis ${ }^{\prime \prime}$,Yasmine M. Hajar", Laureline Treps ${ }^{2}$, Carine Michel ${ }^{\prime}$,Elena A.

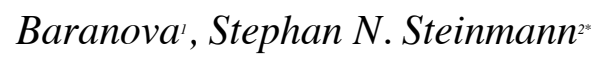

'Department of Chemical and Biological Engineering, Centre for Catalysis Research and Innovation (CCRI), University of Ottawa, 161 Louis-Pasteur, Ottawa, ON K1N 6N5, Canada. Email: elena.baranova@uottawa.ca; Tel: 16135625800 (x 6302); Fax: 16135625172.

¿Univ Lyon, ENS de Lyon, CNRS, Université Lyon 1, Laboratoire de Chimie UMR 5182, F69342, Lyon, France. E-mail: stephan.steinmann@ens-lyon.fr; Fax: +33472728080; Tel: $+33472728847$

"These authors have equally contributed to this work.

*Corresponding author: stephan.steinmann@ens-lyon.fr; $\quad$ Tel: $\quad+33472728847$; Fax: $+33472728080$ 
Abstract: Understanding the role of an electric field on the surface of a catalyst is crucial in tuning and promoting the catalytic activity of metals. Herein, we evaluate the oxidation of methane over a Pt surface with varying oxygen coverage using density functional theory. The latter is controlled by the electrode polarization, giving rise to the Non-Faradaic Modification of Catalytic Activity phenomenon. At $-1 \mathrm{~V}$, the $\operatorname{Pt}(111)$ surface is present, while at $1 \mathrm{~V} \alpha-\mathrm{PtO}_{2}$ on $\operatorname{Pt}(111)$ takes over. Our results demonstrate that the alteration of the Pt-oxide surface under the influence of an electrochemical potential promotes the catalytic activity of the metal-oxides by lowering the activation energy barrier of the reaction.

\section{TOC Graphic}

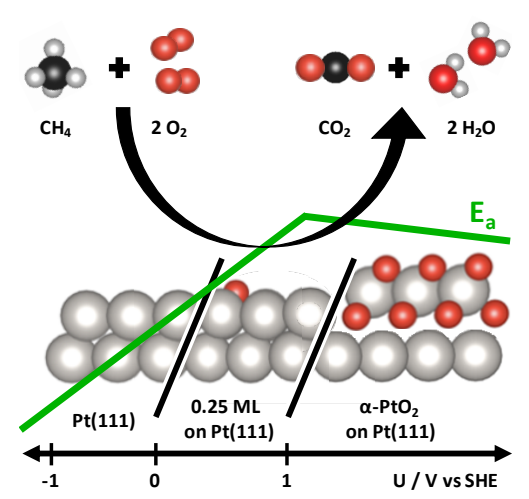


The outcome of chemical reactions can not only be tuned by relative concentrations, pressures and the temperature, but also by the presence of an electric field. The latter is believed to be key in enzymatic and molecular catalysis ${ }^{1-3}$ and also for base-catalyzed reactions on metal surfaces, ${ }^{4}$ and it is directly exploited in field-assisted catalysis ${ }^{5}$ and somewhat more indirectly in electrocatalysis, where the electrochemical potential, rather than the electric field, is controlled. Here, we focus on an intriguing case, the Non-Faradaic Modification of Catalytic Activity (NEMCA) also known as the Electrochemical Promotion of Catalysis (EPOC) phenomenon. ${ }^{6-9}$ This phenomenon is observed for reactions at the solid/gas interface. A typical set up is shown in Figure 1. A metal or an oxide catalyst is deposited on a solid electrolyte (typically yttria-stabilized zirconia, YSZ) to obtain the working electrode ${ }^{6}$. The counter electrode is deposited on the opposite side of this solid electrolyte composed of gold, which is inert for the reaction. Typically, all the electrodes are exposed to the reactants, however the electrochemical enhancement occurs only on the catalyst/working electrode. Upon the application of an electrochemical potential difference between these two electrodes, the (non-electrochemical) catalytic activity is considerably modified (increased or suppressed), an effect that is much greater than the electrochemical reaction that occurs at the solid-gas-catalyst triple-phase boundary (TBP). Since the discovery of EPOC in the early 1980's, over 100 different catalytic reactions have been performed displaying the EPOC effect for various reactions and reactor types. ${ }^{10-12}$ A detailed atomistic understanding of the influence of the electric potential on the surface state and the corresponding catalytic properties is still an active topic of research. ${ }^{13-17}$ Such an insight is a crucial factor in interpreting the experimental observations and putting conclusions from past studies on solid theoretical ground. An elucidation on what is occurring during the reaction could allow for the development of an efficient and novel catalytic electrode design that can fully exploit the power of EPOC, i.e., operate at rather low temperature 
and still display superior catalytic activity for key reactions such as the complete oxidation of methane ${ }^{18.19}, \mathrm{NO}_{x}$ reduction ${ }^{20}$, complete oxidation of volatile organic compounds (VOCs) ${ }^{2123}$ and $\mathrm{CO}_{2}$ hydrogenation ${ }^{2+26}$.

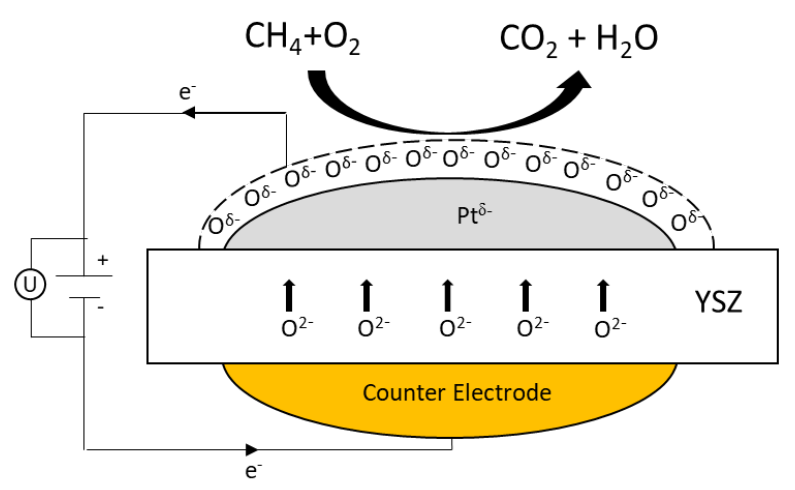

Figure 1. Electrochemical promotion of $\mathrm{Pt}$ for the methane oxidation reaction under a positive polarization in the gas phase. The catalyst/working electrode $(\mathrm{Pt})$ is here exposed to the reactants, methane and $\mathrm{O}_{2}$, which yield $\mathrm{CO}_{2}$ and water. This working electrode is typically accompanied by a counter and reference gold electrode, placed on opposing sides of yttria-stabilized zirconia (YSZ), an oxygen $\left(\mathrm{O}^{*}\right)$ conductive electrolyte. Through the application of a potential difference between the counter and working electrode, oxygen species $\left(\mathrm{O}^{2}\right)$ from YSZ are able to migrate toward the working-catalyst electrode through the solid-gas-catalyst three-phase boundary. ${ }^{10}$

One of the early works focusing on the origin of EPOC was performed in the case of the methane combustion catalyzed by Pt supported over YSZ. ${ }^{2}$ X-ray Photoemission Spectroscopy (XPS), temperature programmed desorption (TPD) and cyclic voltammetry (CV) have consistently evidenced the presence of two distinct oxygen species on Pt surface exposed to $\mathrm{O}_{2}$ under EPOC. ${ }^{2289}$ The first species is already observed in absence of polarization. It is weakly bonded according to TPD and CV, with a binding energy measured at $530.4 \mathrm{eV}$ in XPS. The second one appears after application of a polarization of $+1 \mathrm{~V}$ or $1.6 \mathrm{~mA} \mathrm{~m}^{2}$ depending on the studies. This additional 
species is more strongly bonded (TPD, CV) and shows a shift in binding energy to $528.8 \mathrm{eV}$ (XPS). This second oxygen species is generally assumed to originate from YSZ as a backspillover oxygen species. ${ }^{28}$ Furthermore, isotopic exchange done by Tsampas et al., showed that using ${ }^{18} \mathrm{O}_{2}$ in the gas feed led to an increase in isotopically-labeled $\mathrm{CO}_{2}$ during anodic polarization for the oxidation of propane on $\mathrm{Pt} / \mathrm{YSZ}^{30}$. The production of $\mathrm{CO}_{2}$ under anodic polarization contained $\mathrm{C}^{1 \mathrm{~s}} \mathrm{O}_{2}$ but also $\mathrm{C}^{\prime \circ} \mathrm{O}_{2}$ and $\mathrm{C}^{\prime \prime} \mathrm{O}^{\circledR} \mathrm{O}$, confirming ${ }^{\circledR} \mathrm{O}$ supplied from $\mathrm{YSZ}$ to the $\mathrm{Pt}$ catalyst. From these characterizations emerged the accepted mechanism in EPOC. Not only does the lattice oxygen of YSZ react electrochemically at the triple-phase boundary, it also migrates to the surface of the catalyst to be part of an effective double layer composed of partially charged oxygen with a compensating charge in the metal $\left(\mathrm{O}^{-}-\delta^{+}\right)$. This electrochemical potential induced charge separation generates an electric field. ${ }^{3-35}$ Further studies have led to establish the effect of EPOC on the kinetics depending on the type of reactants known as the rules of electrochemical promotion. ${ }^{3637}$ Several ab initio studies using cluster or periodic models of the catalyst surface were probing the correlation between the applied potential, the change in the catalyst's work function and the strength of adsorption of various adsorbates. ${ }^{43841}$

To identify more precisely the exposed oxygen species and their reactivity under polarization, we have undertaken ab initio computations using $\mathrm{Pt}(111)$ to simulate the influence of polarizing Pt/YSZ. We evaluate the role of the surface polarization (i) on the surface stability of various oxygen species on the Pt surface to clarify and understand the existence and role of the two oxygen species discovered experimentally ${ }^{2030}$ and (ii) evaluate the energy barrier, transition state configurations and reaction pathway for the dissociative adsorption of methane $\left(\mathrm{CH}_{4}\right)$ under the EPOC conditions ${ }^{27}$. We couple ab initio thermodynamics (where the entropy of gas-phase species is taken into account via statistical mechanics), periodic density functional theory computations at 
the PBE-dDsC level of theory ${ }^{42,43}$ with a direct model of the electrochemical potential by solving the linearized Poisson-Boltzmann equation as implemented in VASPsol ${ }^{43}$. This combination, also known as grand-canonical DFT ${ }^{4,45}$, includes a thermodynamic average of the double layer for each intermediate and surface state. In practice, the surface charge is varied and the corresponding electrochemical potential determined. Together with the grand-canonical electronic energy, this allows to establish the (reaction) energy as a function of the electrochemical potential via a parabolic fit. Grand-canonical DFT allows to keep the electrochemical potential constant during any reaction step, in agreement with the experimental setup. The approach has been presented in details before ${ }^{17}$ and applied to the electrochemical interface ${ }^{46}$ and to elucidate reaction mechanisms ${ }^{478}$. In the context of EPOC, where the experimental setup consists of a metal catalyst deposited on a solid electrolyte and exposed to the gas-phase, the surface charge, which modulates the potential in grand-canonical DFT, is best understood as a means to capture the effect of small fractions of oxygen vacancies or adatoms forming the effective double layer ${ }^{17}$. Explicitly modelling these small amounts of surplus oxygen atoms or vacancies would require very large unit cells and a representative phase-space sampling in order to reach the corresponding potentials. Furthermore, the explicit modelling would not easily allow to assess the potential dependence of transition states, in contrast with our approach which computes the energy in function of the potential of each surface species, including the transition state. Within the grand canonical approach, the number of electrons per cell is varied. To neutralize the corresponding negative charge, one may use a homogeneous background charge, but this adds spurious terms to the energy and forces. We have successfully proposed to instead use a Poisson-Boltzmann counter charge (known also as implicit solvent and associated electrolyte) to obtain robust (size-independent) electronic energies in periodic computations. As we show in the supporting information (Fig. S1 and associated 
discussion), the precise settings of this counter-charge model barely impact the qualitative results, even though the quantitative numbers are somewhat dependent on these settings, in agreement with our previous study." Since the default values (dielectric constant of water) provide an upper estimate of the field effects, Fig. S2 presents the analogs to Fig. 2-4 for the opposite extreme (dielectric constant of 1). The EPOC reality is to be expected somewhere in-between.

To start, we have investigated the surface state of $\mathrm{Pt}(111)$ as a function of the pressure of $\mathrm{O}_{2}$ in open-circuit (O.C.) conditions considering various coverages of atomic oxygen from 0.25 ML to $2 \mathrm{ML}$ including sub-surface oxygens, and also an $\alpha-\mathrm{PtO}_{2}$ film grown on $\mathrm{Pt}(111)$. The corresponding structures are shown in Fig. S3 and Fig. S4 and the most pre-eminent ones are reported in Figure 2c. An increasing coverage of oxygen is expected with an increase of pressure or a decrease in temperature. Ab initio thermodynamics indicates that at low pressure of $\mathrm{O}_{2}\left(6.6 \times 10^{*} \mathrm{kPa}\right.$, typically found in the ultra high vacuum chamber of XPS), the $\alpha-\mathrm{PtO}_{2}$ film is the most stable phase up to $350{ }^{\circ} \mathrm{C}, 0.25 \mathrm{ML}$ of atomic oxygen dominates in the $350{ }^{\circ} \mathrm{C}-600{ }^{\circ} \mathrm{C}$ range, and the pristine surface is reached above $600{ }^{\circ} \mathrm{C}$ (Fig. S5). At higher pressure $\mathrm{O}_{2}(1 \mathrm{kPa}$, typically found in EPOC experiments), the temperature range where the $\alpha-\mathrm{PtO}_{2}$ film dominates extends to $700^{\circ} \mathrm{C}$ (Figure 2a). When switching to EPOC conditions, the surface state is also tuned by the applied potential. The corresponding phase diagram is shown in Figure $2 \mathrm{~b}$ for $\mathrm{P}_{\mathrm{o} 2}=1 \mathrm{kPa}$. At $1 \mathrm{~V} / \mathrm{SHE}$, the $\alpha-\mathrm{PtO}_{2}$ film is the most stable phase up to roughly $700^{\circ} \mathrm{C}$, but its prevalence decreases rapidly with a decrease in potential in favor of the intermediate phase B and then the pristine surface, which becomes the most stable phase at roughly $0 \mathrm{~V} / \mathrm{SHE}$. To be more representative, the ratio of the surface free energies for $\mathrm{Pt}(111), 0.25 \mathrm{ML} \mathrm{O}-\mathrm{Pt}(111)$ and $\alpha-\mathrm{PtO}_{2}$ film is given as a function of the potential at $\mathrm{P}_{\mathrm{o} 2}=1 \mathrm{kPa}$ and $600{ }^{\circ} \mathrm{C}$ in Figure 2b. It shows a subtler picture, with 0.25 ML O-Pt(111) 
already appearing at $-0.5 \mathrm{~V} / \mathrm{SHE}$ and co-existing with the $\alpha-\mathrm{PtO}_{2}$ film in a wide range of potential (0 to $0.75 \mathrm{~V} / \mathrm{SHE})$.

Experimentally, the two oxygen species that were evidenced have a difference in binding energy of $1.6 \mathrm{eV}$ (XPS) ${ }^{28}$. This difference matches perfectly the difference between the computed binding energies of 0.25 ML O-Pt(111) $(539.5 \mathrm{eV})$ and the averages of the signals for the $\alpha$ $\mathrm{PtO}_{2} @ \mathrm{Pt}(111)$ film $(537.7 \mathrm{eV}$ and $538.1 \mathrm{eV})$ while phases such as surface $\alpha-\mathrm{PtO}_{2}$ (only one peak at $542.5 \mathrm{eV}$ ) or bulk $\alpha-\mathrm{PtO}_{2}(534.1 \mathrm{eV})$ can be discarded. Thus, we propose that the first oxygen species identified experimentally corresponds to atomic oxygen adsorbed on Pt at a coverage around 0.25 ML: this species is likely to be found on Pt in presence of oxygen and should be rather weakly bonded. The $\alpha-\mathrm{PtO}_{2}$ film is found to be more stable under a low temperature/high pressure of $\mathrm{O}_{2}$, but it is very likely to be hard to access in a limited amount of time due to kinetic limitations. The barrier of formation apparently can be overcome under EPOC conditions of oxidizing potentials of $1 \mathrm{~V}$ or $1.6 \mathrm{~mA} \mathrm{~m} \mathrm{~m}^{2}$ : the $\alpha-\mathrm{PtO}_{2}$ film grows with time, showing oxygen species with a downshift in binding energy in XPS, identified here as the second oxygen species. The same kinetic limitation applies to its transformation back to pristine Pt or atomic oxygen adsorbed on Pt, explaining why this second species appears as more strongly bonded. In EPOC conditions, the Pt catalyst surface is covered by a mixture of these two species, indiscriminately incorporating oxygen atoms originating from the gas phase and from the YSZ. The main role of the YSZ is not here to provide a specific type of oxygen species but to conduct ions and ensure a strong electrostatic field at the surface. 


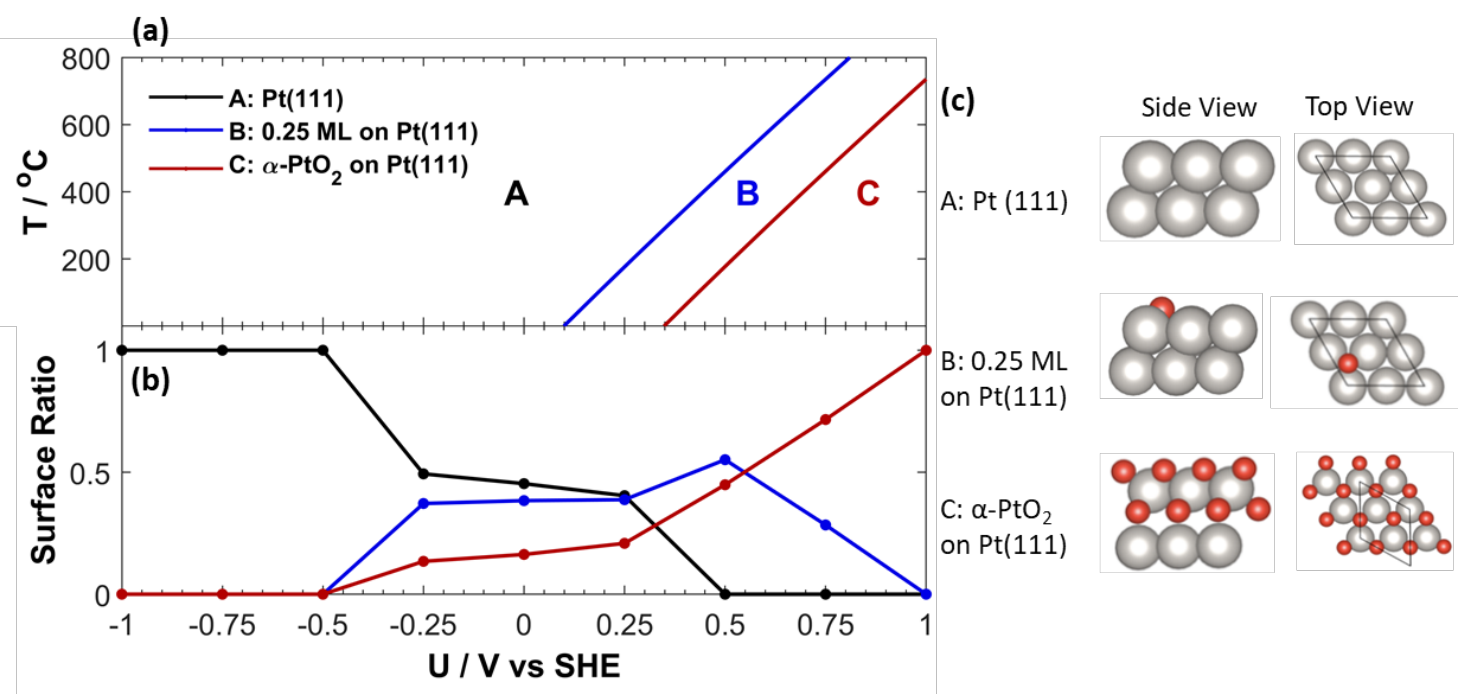

Figure 2. Ab initio thermochemistry, structures and proportions of surfaces, displaying (a) surface phase diagrams and (b) surface ratio as a function of potential and (c) representing the corresponding structures. $\mathrm{P}_{\mathrm{o} 2}=1 \mathrm{kPa}$ and $600{ }^{\circ} \mathrm{C}$, for the ratio $(\mathrm{b})$.

The application of a potential not only tunes the oxygen species present on $\mathrm{Pt}$, it also tunes the methane oxidation kinetics: Vayenas et al. have shown that when performed at $600-750{ }^{\circ} \mathrm{C}$, this reaction displays an inverted-volcano behavior, with an increase in the $\mathrm{CO}_{2}$ production rate during positive and negative polarization ${ }^{37}$ Having determined the nature of the oxygen species present on the catalyst surface as a function of the potential, we investigate here the influence of the surface state and of the potential on the $\mathrm{C}-\mathrm{H}$ activation of methane. According to experimental evidence, the first $\mathrm{C}-\mathrm{H}$ activation step is the rate-limiting step towards $\mathrm{CO}_{2}$ formation ${ }^{49-51}$. Therefore, we only investigate the first, dissociative adsorption of methane as a function of the potential, as the later steps in the reaction mechanism are expected to go smoothly. For each surface state, the activation energy and the reaction energy are reported as a function of the potential in Figure $3 . \mathrm{On} \operatorname{Pt}(111)$ (black), the $\mathrm{C}-\mathrm{H}$ activation goes through a typical three-center transition state with an activation energy of $0.84 \mathrm{eV}$ and an athermic reaction energy of $0.06 \mathrm{eV}$ under O.C. conditions. This process 
is favored by the application of a potential only above $0.4 \mathrm{~V} / \mathrm{SHE}$. In presence of spectator coadsorbed oxygen (0.25 ML O-Pt(111)), the activation energy of the $\mathrm{C}-\mathrm{H}$ scission is pushed up above $1.3 \mathrm{eV}$ in O.C. conditions (Fig. S11a). An alternative path involves a direct participation of co-adsorbed $\mathrm{O}$ in the dissociation process. When used as a hydrogen-abstraction species yielding adsorbed $\mathrm{OH}$, the co-adsorbed $\mathrm{O}$ leads to a decrease of roughly $0.1 \mathrm{eV}$ of the activation energy and $0.2 \mathrm{eV}$ in reaction energy compared with the spectator case (Fig. S11b). The evolution of the corresponding activation energy and reaction energy with the applied potential are shown in Fig. 3 in blue. They follow again the same trend as $\mathrm{Pt}(111)$ but to a weaker extent. Last, on the $\alpha-\mathrm{PtO}_{2}$ film two possible $\mathrm{CH}_{4}$ dissociation pathways were considered (Fig. S12). For the best case, $\mathrm{CH}_{4}$ dissociatively adsorbs on $\mathrm{Pt}$ and the $\mathrm{H}$ is transferred to the nearest $\mathrm{O}$ to form $\mathrm{OH}$, analogously to the $0.25 \mathrm{ML}$ case. The corresponding barriers and reaction energies are always above $1.9 \mathrm{eV}$ and $1.3 \mathrm{eV}$ respectively in the potential range $-1 ;+1 \mathrm{~V} / \mathrm{SHE}$. Again, positive polarization results in a decrease in the energy barrier over the O.C. value (in red). 
(a)

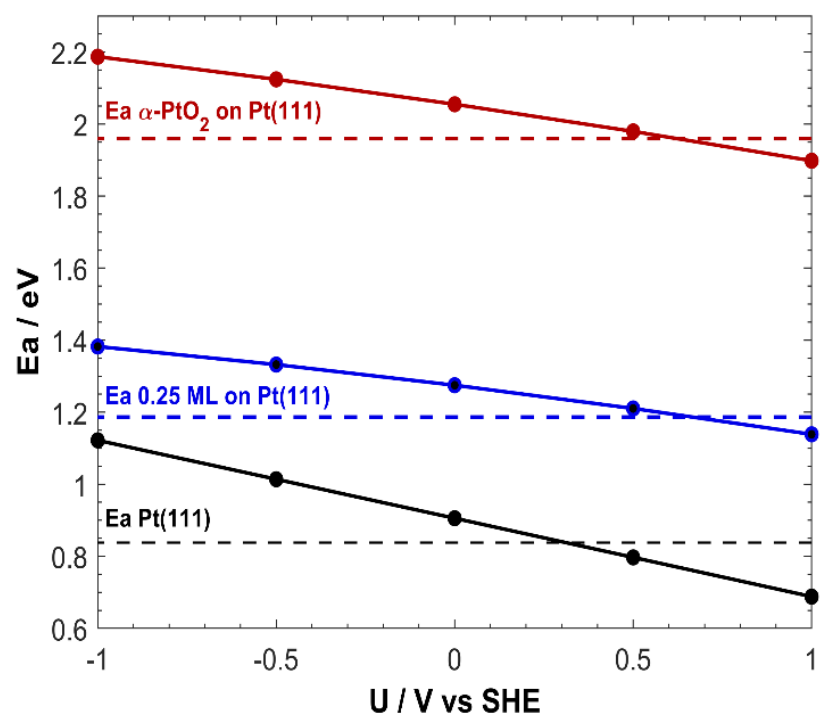

(b)

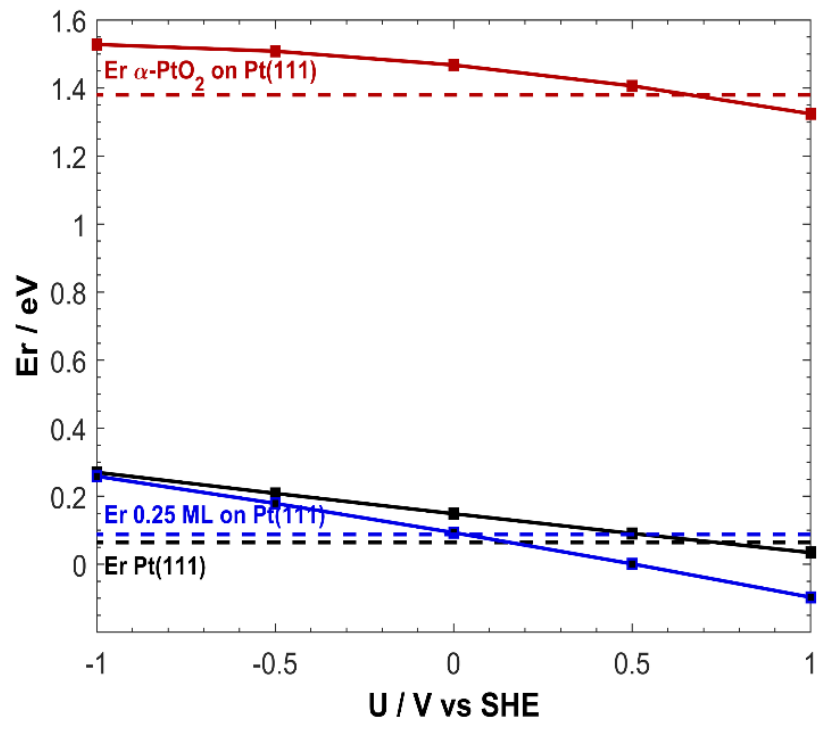

Figure 3. Summary of the first C-H scission in methane (a) activation energy Ea and (b) reaction energy Er for Pt(111), 0.25 ML on Pt(111), and $\alpha$-PtO2 film on Pt(111). The dotted line represents the O.C. value, a complete analysis can be found in Fig. S9, S11 and S13.

The systematic increases in the activation energy (Ea) and reaction energy (Er) when switching to a more negative potential seems at a first sight incompatible with the experimentally observed increase in rate under negative polarization. As a first hypothesis the $\mathrm{O}_{2}$ dissociation mechanism was evaluated on $\mathrm{Pt}(111)$. The activation and reaction energies of the $\mathrm{O}_{2}$ dissociation into adsorbed atomic $\mathrm{O}$ are displayed in Fig. S14. The activation energy linearly decreases as the potential becomes more negative. However, the $\mathrm{O}_{2}$ dissociation activation energy is lower than the one of the dissociation of $\mathrm{CH}_{4}$ on the various surfaces of $\mathrm{Pt}$ at all potentials considered. Thus, it is not enough to justify the inverted-volcano behavior obtained with the Pt catalyst under negative polarization. This points to the second hypothesis: the inverted volcano is enrooted in the changes of the surface state, which is more (pristine $\mathrm{Pt}(111))$ or less (0.25 ML O-Pt(111) and $\alpha-\mathrm{PtO}_{2}$ film) favourable to the methane activation. Taking into account the relative amount of each surface 
termination according to Fig. 2b, the resulting effective activation barrier is plotted as a function of the applied potential in Fig. 4, together with the corresponding experimental activation energy. ${ }^{27}$ Activation energy values were taken from Fig. 12 in ref. ${ }^{27}$, where Vayenas et al., reported their results as a function of the potential difference with respect to O.C. (maximum value in Fig. 12 from ref. ${ }^{27}$ ). Furthermore, to match our computed O.C. value, the experimental Ea values were shifted by $1.5 \mathrm{eV}$. While there is a nice agreement for the negative branch, the slope of the computed positive branch $(>1 \mathrm{~V})$ is not as steep as the experimental one. This can be due to the formation of active sites that we did not evaluate such as corners, edges or simply rough $\alpha-\mathrm{PtO}_{2}$ islands or other surface oxide arrangements. ${ }^{523}$ Furthermore, even when minimizing the field effects by using a dielectric constant of 1 (Fig. S2) the qualitative features do not change, confirming the evolution of the surface state as the origin of the potential dependent activation energy rather than electric field effects. 


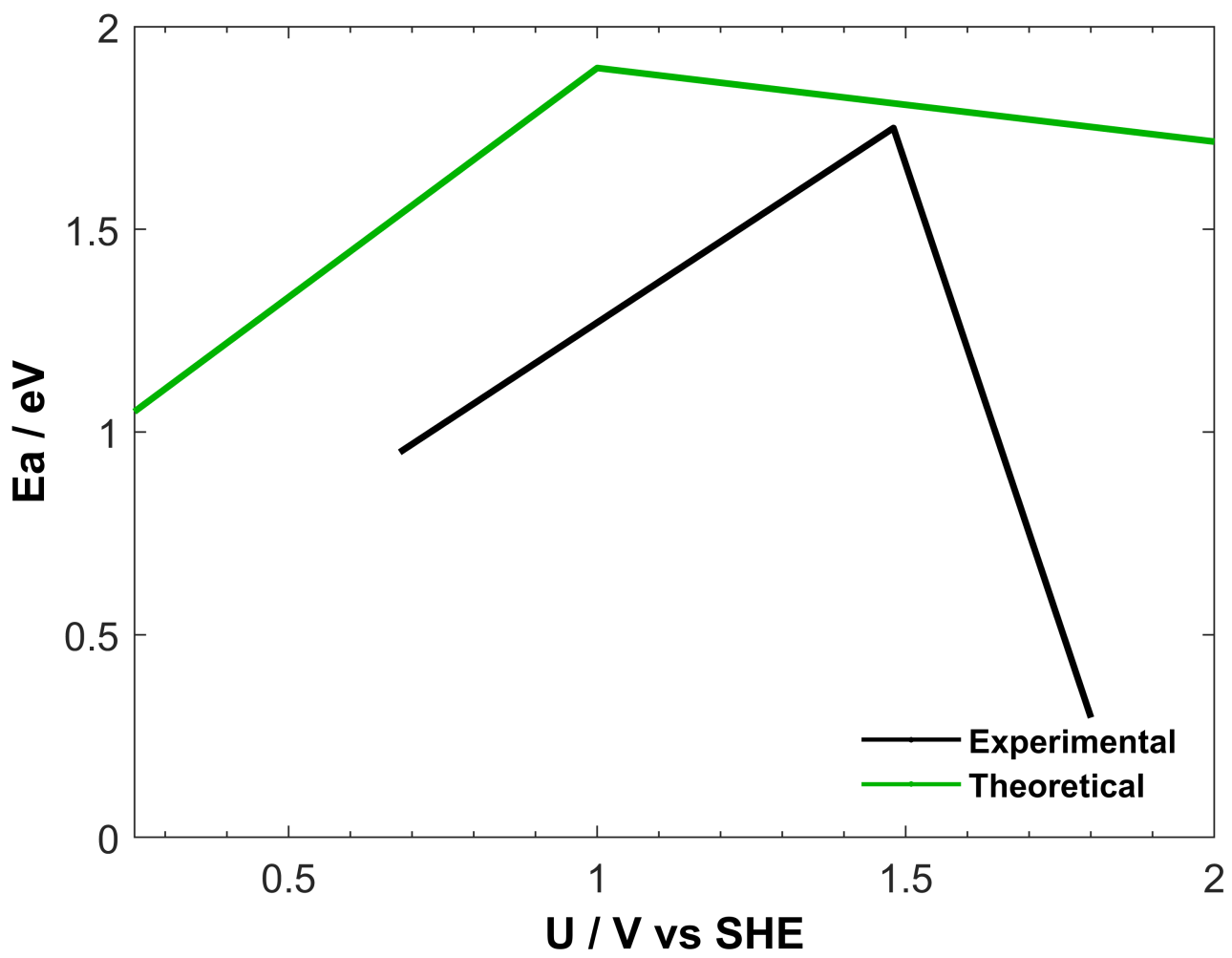

Figure 4. Activation energy vs potential, comparing experimental methane oxidation and the computed activation energy of the first $\mathrm{C}-\mathrm{H}$ scission of methane. Experimental data was taken from ref. ${ }^{27}$ where the potential difference represents a change from O.C. value and theoretical V vs SHE. Based on our computations, we estimated the experimental O.C. potential as $1.5 \mathrm{~V}$ vs SHE.

In brief, combining our computational model with published catalytic tests, XPS and TPD, we unequivocally resolved the riddle of the "two oxygen species" seen experimentally as spatially separated zones of adsorbed atomic oxygen on $\mathrm{Pt}$ and patches of $\alpha-\mathrm{PtO}_{2}$. Both species can incorporate oxygen atoms of both the $\mathrm{O}_{2}$ gas phase and the YSZ electrolyte and activate methane, with an activation barrier that diminishes with an increase in the applied potential. With increasingly reductive potentials, the surface is more and more protected from oxygen. Eventually 
a surface state with patches of pristine Pt is reached, which acts as a very powerful catalyst to activate the $\mathrm{C}-\mathrm{H}$ bond. Thus, the observed inverted-volcano under EPOC is here mainly traced back to a potent tuning of the surface state by varying the proportions of the different exposed surfaces. This deeper understanding is essential to use EPOC to favor a reaction, design a specific catalytic surface and reverse inactive catalytic states. Importantly, our results clarify the atomistic origin of EPOC on methane oxidation over Pt as a weak electric field effect on the one hand and a potential-tuned surface state on the one hand, suggesting that effects that are ascribed directly to electric field might sometimes be over-considered.

\section{Acknowledgments}

The authors thank the University of Ottawa, CNRS, and ENS Lyon for support of research conducted within the context of the International Associated Laboratory 'Fundamental catalysis for green chemistry: From well-defined active sites to mechanistic explorations - FUNCAT' and the Natural Sciences and Engineering Research Council of Canada (NSERC) for financial support. The authors thank the SYSPROD project and AXELERA Pôle de Compétitivité for financial support (PSMN Data Center). Yasmine Hajar thanks NSERC for the Vanier Canada Graduate scholarship support.

\section{Supporting Information Available}

Calculation and computational details, surface structures, surface free energy details, activation and reaction energy details

\section{References}

(1) Warshel, A. Electrostatic Basis of Structure-Function Correlation in Proteins. Acc. Chem. Res. 1981, 14, 284-290. 
(2) Blyth, M. T.; Noble, B. B.; Russell, I. C.; Coote, M. L. Oriented Internal Electrostatic Fields Cooperatively Promote Ground- And Excited-State Reactivity: A Case Study in Photochemical $\mathrm{CO}_{2}$ Capture. J. Am. Chem. Soc. 2020, 142, 606-613.

(3) Stuyver, T.; Danovich, D.; Joy, J.; Shaik, S. External Electric Field Effects on Chemical Structure and Reactivity. Wiley Interdiscip. Rev. Comput. Mol. Sci. 2019, 10, 1-22.

(4) Wang, P.; Steinmann, S. N.; Fu, G.; Michel, C.; Sautet, P. Key Role of Anionic Doping for H2 Production from Formic Acid on Pd(111). ACS Catal. 2017, 7, 1955-1959.

(5) Che, F.; Gray, J. T.; Ha, S.; Kruse, N.; Scott, S. L.; McEwen, J. S. Elucidating the Roles of Electric Fields in Catalysis: A Perspective. ACS Catal. 2018, 8, 5153-5174.

(6) Vayenas, C. G.; Bebelis, S.; Pliangos, C.; Brosda, S.; Tsiplakides, D. Electrochemical Activation of Catalysis: Promotion, Electrochemical Promotion, and Metal-Support Interactions; Springer: New York; 2001.

(7) Vernoux, P.; Lizarraga, L.; Tsampas, M. N.; Sapountzi, F. M.; De Lucas-Consuegra, A.; Valverde, J. L.; Souentie, S.; Vayenas, C. G.; Tsiplakides, D.; Balomenou, S.; Baranova, E. A. Ionically Conducting Ceramics as Active Catalyst Supports. Chem. Rev. 2013, 113, 8192-8260.

(8) Vayenas, C. G. Promotion, Electrochemical Promotion and Metal-Support Interactions: Their Common Features. Catal. Letters 2013, 143, 1085-1097.

(9) Vernoux, P. Catalysis: Volume 29 Recent Advances in Electrochemical Promotion of Catalysis; The Royal Society of Chemistry; 2017.

(10) Wagner, C. Adsorbed Atomic Species as Intermediates in Heterogeneous Catalysis. Adv. Catal. 1970, 21, 323-381.

(11) Katsaounis, A. Recent Developments and Trends in the Electrochemical Promotion of 
Catalysis (EPOC). J. Appl. Electrochem. 2010, 40, 885-902.

(12) Vernoux, P.; Guth, M.; Li, X. Ionically Conducting Ceramics as Alternative Catalyst Supports. Electrochem. Solid-State Lett. 2009, 12, 9-11.

(13) Goodpaster, J. D.; Bell, A. T.; Head-Gordon, M. Identification of Possible Pathways for CC Bond Formation during Electrochemical Reduction of $\mathrm{CO}_{2}$ : New Theoretical Insights from an Improved Electrochemical Model. J. Phys. Chem. Lett. 2016, 7, 1471-1477.

(14) Xiao, H.; Shin, H.; Goddard, W. A. Synergy Between Fe and Ni in the Optimal Performance of (Ni,Fe)OOH Catalysts for the Oxygen Evolution Reaction. Proc. Natl. Acad. Sci. U. S. A. 2018, $115,5872-5877$.

(15) Ringe, S.; Clark, E. L.; Resasco, J.; Walton, A.; Seger, B.; Bell, A. T.; Chan, K. Understanding Cation Effects in Electrochemical $\mathrm{CO}_{2}$ Reduction. Energy Environ. Sci. 2019, 12, 3001-3014.

(16) Goldsmith, Z. K.; Secor, M.; Hammes-Schiffer, S. Inhomogeneity of Interfacial Electric Fields at Vibrational Probes on Electrode Surfaces. ACS Cent. Sci. 2020, 6, 304-311.

(17) Hajar, Y. M.; Treps, L.; Michel, C.; Baranova, E. A.; Steinmann, S. N. Theoretical Insight into the Origin of the Electrochemical Promotion of Ethylene Oxidation on Ruthenium Oxide. Catal. Sci. Technol. 2019, 9, 5915-5926.

(18) Kalaitzidou, I.; Zagoraios, D.; Brosda, S.; Katsaounis, A.; Vernoux, P.; Vayenas, C. G. Electrochemical Promotion of Methane Oxidation on Pd Nanoparticles Deposited on YSZ. Mater. Today Proc. 2018, 5, 27345-27352.

(19) Hajar, Y. M.; Venkatesh, B.; Houache, M. S. E.; Liu, H.; Safari, R.; Prabhudev, S.; Botton, G. A.; Baranova, E. A. Electrochemical Promotion of Bi-Metallic Ni9Pd Core Double-Shell Nanoparticles for Complete Methane Oxidation. J. Catal. 2019, 374, 127-135. 
(20) Dorado, F.; Lucas-consuegra, A. De; Vernoux, P. Electrochemical Promotion of Platinum Impregnated Catalyst for the Selective Catalytic Reduction of NO by Propene in Presence of Oxygen. Appl. Catal. B Environ. 2007, 73, 42-50.

(21) Dole, H. A. E.; Isaifan, R. J.; Sapountzi, F. M.; Lizarraga, L.; Aubert, D.; Princivalle, A.; Vernoux, P.; Baranova, E. A. Low Temperature Toluene Oxidation over Pt Nanoparticles Supported on Yttria Stabilized-Zirconia. Catal. Letters 2013, 143, 996-1002.

(22) Hajar, Y. M.; Dole, H. A.; Couillard, M.; Baranova, E. A. Investigation of Heterogeneous Catalysts by Electrochemical Method: Ceria and Titania Supported Iridium for Ethylene Oxidation. ECS Trans. 2016, 72, 161-172.

(23) Hajar, Y. M.; Patel, K. D.; Tariq, U.; Baranova, E. A. Functional Equivalence of Electrochemical Promotion and Metal Support Interaction for $\mathrm{Pt}$ and $\mathrm{RuO}_{2}$ Nanoparticles. J. Catal. 2017, 352, 42-51.

(24) Kalaitzidou, I.; Makri, M.; Theleritis, D.; Katsaounis, A.; Vayenas, C. G. Comparative Study of the Electrochemical Promotion of $\mathrm{CO} 2$ Hydrogenation on Ru Using $\mathrm{Na}+, \mathrm{K}+, \mathrm{H}+$ and $\mathrm{O}^{2}$ Conducting Solid Electrolytes. Surf. Sci. 2016, 646, 194-203.

(25) Panaritis, C.; Zgheib, J.; Ebrahim, S. A. H.; Couillard, M.; Baranova, E. A. Electrochemical In-Situ Activation of Fe-Oxide Nanowires for the Reverse Water Gas Shift Reaction. Appl. Catal. B Environ. 2020, 269, 118826.

(26) Panaritis, C.; Michel, C.; Couillard, M.; Baranova, E. A.; Steinmann, S. N. Elucidating the Role of Electrochemical Polarization on the Selectivity of the $\mathrm{CO}_{2}$ Hydrogenation Reaction over Ru. Electrochim. Acta 2020, 350, 136405.

(27) Tsiakaras, P.; Vayenas, C. G. Non-Faradaic Electrochemical Modification of Catalytic Activity. VII. The Case of Methane Oxidation on Platinum. J. Catal. 1993, 140, 53-70. 
(28) Ladas, S.; Kennou, S.; Bebelis, S.; Vayenas, C. G. Origin of Non-Faradaic Electrochemical Modification of Catalytic Activity. J. Phys. Chem. 1993, 97, 8845-8848.

(29) Neophytides, S. G.; Vayenas, C. G. TPD and Cyclic Voltammetric Investigation of the Origin of Electrochemical Promotion in Catalysis. J. Phys. Chem. 1995, 99, 17063-17067.

(30) Tsampas, M. N.; Sapountzi, F. M.; Boréave, A.; Vernoux, P. Isotopical Labeling Mechanistic Studies of Electrochemical Promotion of Propane Combustion on Pt/YSZ. Electrochem. commun. 2013, 26, 13-16.

(31) Nicole, J.; Tsiplakides, D.; Pliangos, C.; Verykios, X. E. E.; Comninellis, C.; Vayenas, C. G. G. Electrochemical Promotion and Metal-Support Interactions. J. Catal. 2001, 204, $23-$ 34.

(32) Bebelis, S.; Vayenas, C. G. Non-Faradaic Electrochemical Modification of Catalytic Activity. 1. The Case of Ethylene Oxidation on Pt. J. Catal. 1989, 118, 125-146.

(33) Vayenas, C. G.; Koutsodontis, C. G. Non-Faradaic Electrochemical Activation of Catalysis. J. Chem. Phys. 2008, 128, 182506.

(34) Yentekakis, I. V. V.; Vayenas, C. G. G. The Effect of Electrochemical Oxygen Pumping on the Steady-State and Oscillatory Behavior of CO Oxidation on Polycrystalline Pt. J. Catal. 1988, $111,170-188$.

(35) Vayenas, C. G.; Bebelis, S. Electrochemical Promotion of Heterogeneous Catalysis. Catal. Today 1999, 51, 581-594.

(36) Brosda, S.; Vayenas, C. G. Rules and Mathematical Modeling of Electrochemical and Classical Promotion: 2. Modeling. J. Catal. 2002, 208, 38-53.

(37) Brosda, S.; Vayenas, C. G.; Wei, J. Rules of Chemical Promotion. Appl. Catal. B Environ. 2006, 68, 109-124. 
(38) Pacchioni, G.; Illas, F.; Neophytides, S.; Vayenas, C. G. Quantum-Chemical Study of Electrochemical Promotion in Catalysis. J. Phys. Chem. 1996, 100, 16653-16661.

(39) Pacchioni, G.; Lomas, J. R.; Illas, F. Electric Field Effects in Heterogeneous Catalysis. J. Mol. Catal. A Chem. 1997, 119, 263-273.

(40) Peljo, P.; Manzanares, J. A.; Girault, H. H. Contact Potentials, Fermi Level Equilibration, and Surface Charging. Langmuir 2016, 32, 5765-5775.

(41) Steinmann, S. N.; Michel, C.; Schwiedernoch, R.; Sautet, P. Impacts of Electrode Potentials and Solvents Onthe Electroreduction of $\mathrm{CO}_{2}$ : A Comparison Oftheoretical Approaches. Phys. Chem. Chem. Phys. 2015, 17, 13949.

(42) Kresse, G.; Hafner, J. Ab Initio Molecular Dynamcis for Liquid Metals. Phys. Rev. B 1993, $47,558$.

(43) Kresse, G.; Furthmiiller, J. Efficiency of Ab-Initio Total Energy Calculations for Metals and Semiconductors Using a Plane-Wave Basis Set. Comput. Mater. Sci. 1996, 6, 15-50.

(44) Sundararaman, R.; Goddard, W. A.; Arias, T. A. Grand Canonical Electronic DensityFunctional Theory: Algorithms and Applications to Electrochemistry. J. Chem. Phys. 2017, $146,114104$.

(45) Hörmann, N. G.; Andreussi, O.; Marzari, N. Grand Canonical Simulations of Electrochemical Interfaces in Implicit Solvation Models. J. Chem. Phys. 2019, 150, 041730.

(46) Steinmann, S. N.; Sautet, P. Assessing a First-Principles Model of an Electrochemical Interface by Comparison with Experiment. J. Phys. Chem. C 2016, 120, 5619-5623.

(47) Curutchet, A.; Colinet, P.; Michel, C.; Steinmann, S. N.; Le Bahers, T. Two-Sites Are Better than One: Revisiting the OER Mechanism on CoOOH by DFT with Electrode Polarization. Phys. Chem. Chem. Phys. 2020, 22, 7031-7038. 
(48) Shang, R.; Steinmann, S. N.; Xu, B. Q.; Sautet, P. Mononuclear Fe in N-Doped Carbon: Computational Elucidation of Active Sites for Electrochemical Oxygen Reduction and Oxygen Evolution Reactions. Catal. Sci. Technol. 2020, 10, 1006-1014.

(49) Psofogiannakis, G.; St-Amant, A.; Ternan, M. Methane Oxidation Mechanism on Pt(111): A Cluster Model DFT Study. J. Phys. Chem. B 2006, 110, 24593-24605.

(50) Latimer, A. A.; Kakekhani, A.; Kulkarni, A. R.; Nørskov, J. K. Direct Methane to Methanol: The Selectivity-Conversion Limit and Design Strategies. ACS Catal. 2018, 8, 6894-6907.

(51) Chen, J.; Arandiyan, H.; Gao, X.; Li, J. Recent Advances in Catalysts for Methane Combustion. Catal. Surv. from Asia 2015, 19, 140-171.

(52) Van Spronsen, M. A.; Frenken, J. W. M.; Groot, I. M. N. Observing the Oxidation of Platinum. Nat. Commun. 2017, 8, 429.

(53) Hanselman, S.; McCrum, I. T.; Rost, M. J.; Koper, M. T. M. Thermodynamics of the Formation of Surface $\mathrm{PtO}_{2}$ Stripes on $\mathrm{Pt}(111)$ in the Absence of Subsurface Oxygen . Phys. Chem. Chem. Phys. 2020, 22, 10634-10640. 